\title{
Motivations for Going to University: A Qualitative Study and Class Project
}

Heather Schmidt, Nicole Carocci, Chris Gardner, Alicia Serroul, \& Megan Topalovic, Cape Breton University

\begin{abstract}
We explored student motivations for attending university, including how motivations may change over the course of one's postsecondary career, by conducting semi-structured interviews with 8 upper-year undergraduates. Participants were also asked to reflect back on their own experiences and provide advice for new university students. We conducted a grounded theory analysis to identify common themes running across the 8 interviews. What emerged was a pattern of transition from a predominance of external/extrinsic motivators at the beginning of one's university career, into increasingly internal/intrinsic motivators as students discovered their passions and interests. Two unexpected external/extrinsic themes to emerge included: 'unhelpful high-school guidance-counselling' and 'motivation to disprove people who underestimate you'. The strongest internal/intrinsic motivation was 'desire to help others'. Students can apply these findings to their own lives and as well, universities can gain a better understanding of the supports that are needed to retain students through to graduation.
\end{abstract}

We designed this interview study as a term-project for a third-year psychology course called 'Qualitative Methods in Psychology'. Rather than only learning about qualitative research, collaborating on this study allowed the 4 student-researchers to gain proficiency and experience with all phases of a qualitative study: from initial design and ethics approval, through to analysis and a poster presented at the 2013 STLHE conference. Afterward, one student-researcher stated that it was "fun and exciting to feel more like a colleague [of the professor], rather than just a student" while another said it was "different than other kinds of courses offered [and] felt fresh." I (the professor Heather Schmidt) hoped that this sparked a sustained interest in learning about the world for the students, in addition to an appreciation for sound qualitative research practices.

Our goal was to acquire an in-depth understanding of undergraduate students' motivations for attending university, including how these motivations may change over the course of earning one's degree. The students decided to explore this particular topic because they were interested in reflecting back on their own experiences as undergraduates and were excited by the prospect of hearing what their peers had to say about the same topic. What would they have in common? In what ways might their experiences differ?

Our literature review suggested that encouragement to attend university from both one's family and one's high-school is a very important initial motivator (Woosley \& Shepler, 2011). As is exposure to role-models who have earned university degrees and who can impart 'university-related knowledge' to ease the student into the post-secondary experience (YorkAnderson \& Bowman, 1991). These also impact subsequent success as a student. However, this inherently gives so-called 'traditional students' (i.e., those from a higher socioeconomic class, who enter university full-time immediately after high-school, often with scholarships) a distinct advantage over 'non-traditional students' (i.e., those from lower socioeconomic classes, who are often the first in their family to attend university, are employed while attending classes, pay full- 
fees, and may be older) (Munro, 2011). Non-traditional students receive significantly less exposure to role models and less encouragement from their family, from high school teachers/counsellors, and in the form of scholarships to pursue post-secondary education (Saenz $\&$ Barrera, 2007). In spite of this, non-traditional students are attending university in increasing numbers (Munroe, 2011). Universities need to adapt by better understanding how to support nontraditional students. Without supports in place to ease the initial adjustment period in the first few years, non-traditional students are less likely to continue through to graduation (Woosley \& Shelper, 2011).

Saenz and Barrera (2007) also found that tuition costs are more salient for non-traditional students, because they are less likely to receive scholarships and more likely working full- or part-time while attending classes to pay for their education. They are also more likely to be conscious of the fact that a university degree increases earning potential. Sometimes called the "consumer view of education", this nurtures extrinsic motivation (i.e., pursuit of an activity to gain an external reward or to avoid undesirable consequences) (Monroe, 2011). This may be problematic because Pan and Gauvain (2012) have found that university students with stronger intrinsic motivation (i.e., pursuit of an activity as an end in itself because it is rewarding and enjoyable) have more positive outcomes in their learning, lower stress levels, and a more positive adjustment to university. An extrinsic consumer-view of education can further disadvantage nontraditional students and decrease their chances of success at university.

\section{Methods}

\section{Participants}

Using a combination of convenience sampling and purposive sampling, we recruited 8 participants from the student population at Cape Breton University; all were in their third year of study or higher. Because this was the student-researchers' first experience with qualitative research, they began by interviewing each other. Although the students selected the remaining 4 participants from among their acquaintances, we ensured that characteristics of both traditional and non-traditional students were represented. We discovered it was difficult to find students who fit cleanly into the categories of either 'traditional' or 'non-traditional' students, however, $4 / 8$ reported being employed while attending classes, $3 / 8$ were the first-generation in their family to attend university, and 3/8 reported their parents' socioeconomic status as being 'low' or 'medium-low'. The majority of participants, however, were in their early twenties (7/8), carrying student loans/debt (7/8), psychology majors (6/8), women (6/8), and from the local area (5/8). Interestingly, $5 / 8$ also reported having changed their major at least once.

\section{Procedure}

After demographics questions, the core interview questions included: (a) "Please tell me about your original motivations for going to university," (b) "In what ways have your motivations changed or evolved since then?" and (c) "Looking back on your own experiences, what advice would you give to other students?" By asking them to share advice for other students, we created an opportunity for them to serve as role models and to feel empowered about helping others. One week prior to each interview, the participants were provided with a copy of the interview questions, giving them (a) an opportunity to reflect on the questions and (b) enough information to make an informed decision about whether they wished to participate. The student-researchers digitally recorded, and transcribed each interview. Then, working together in class, we 
collaboratively analyzed the data using grounded theory to pull out reoccurring themes and patterns.

\section{Results}
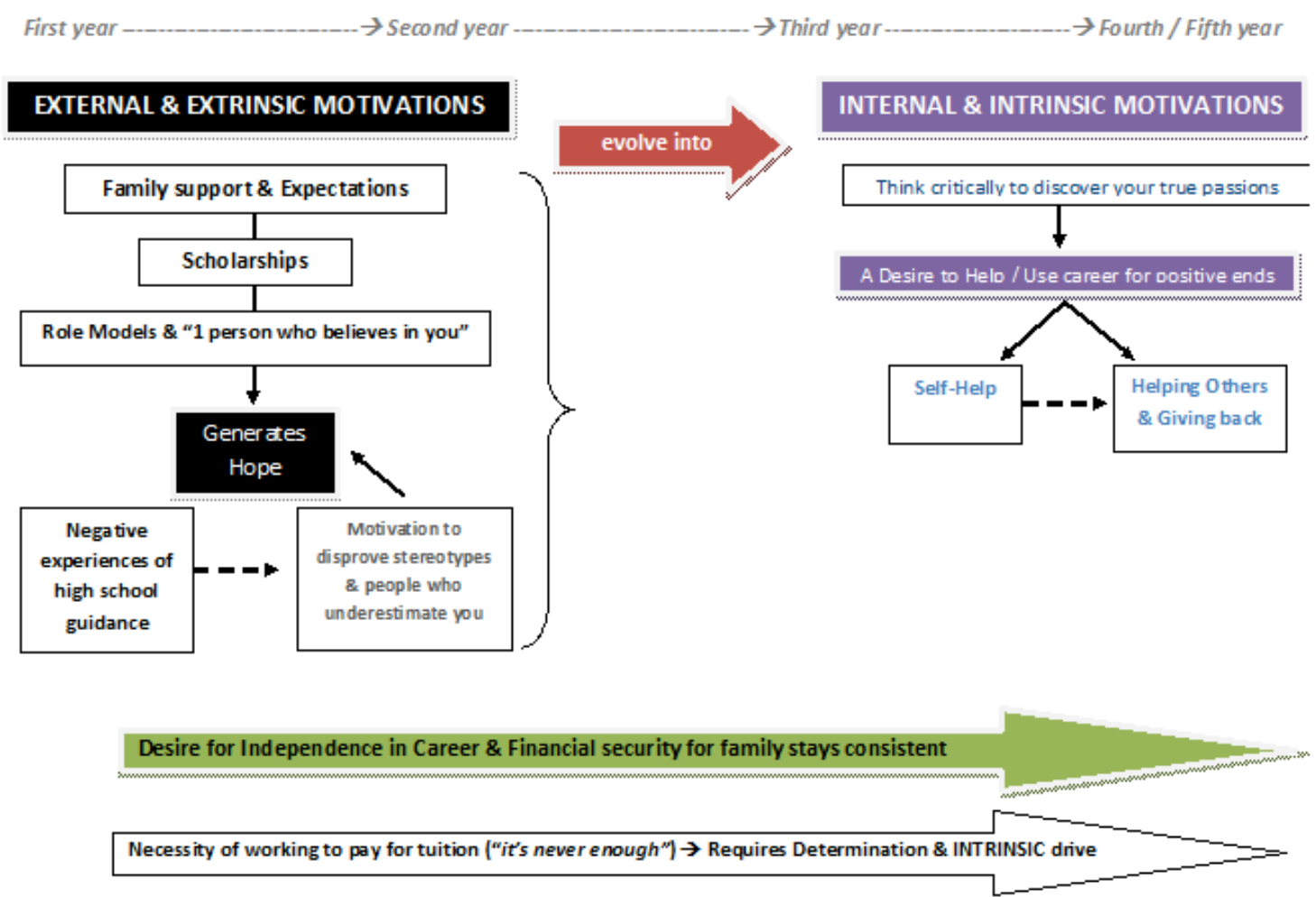

Figure 1 Visual overview of themes

Figure 1 depicts the themes that emerged from the transcripts. Two themes stayed consistent across the students' university career: (a) an extrinsic desire to eventually achieve selfdetermination and financial security for one's (future) family (voiced by $7 / 8$ participants), and (b) the ongoing challenge of finding enough money to pay for one's education, which was mentioned by all 8 participants. As one individual explained, no matter how much you work, "it's never enough". To make all of the effort and hard work worthwhile, however, they stated that it eventually became necessary to find internal/intrinsic motivation, in addition to this original desire "for going to university [...] to direct myself towards a job that would be able to support me in the long run."

Looking back, $7 / 8$ participants stated that their original decision to pursue post-secondary education had been heavily influenced by other people, which could take the form of expectations and/or pressure from family and peers, on one hand, to encouragement from role models and the presence of "one person to believe in you" on the other, particularly if a student was among the first in their family to attend university. 
Initially it was pressure that I felt to go to school. Because I have doctors [and] lawyers in my family, so I think it was intended that this [is] the path I was going to follow. I felt I'm letting people down if I'm only doing an arts [degree] or something simple.

My aunt and uncle: [...] both know what it takes to be in university: the struggle, the stress, the papers, the tests. Just to have them in my corner to understand what I'm going through, it really helps.

A lot of my family has gone to university. So I guess in a way, it was who I knew that was kind of pushing me. Like these are the people who succeeded in my life and I want to succeed like they did.

Receiving scholarships was another factor that initially motivated $6 / 8$ students to enter university. An unexpected finding was that $7 / 8$ participants shared negative experiences of highschool guidance-counselling, in which they reported being discouraged from "setting their sights too high". Instead of exploring or challenging themselves, students were advised to pursue less ambitious options:

They basically decided that my math marks were never good through high school. And they decided that I should just take an arts program, and I should never look at any of the sciences. They were trying to push me towards trades. But all my other marks were 90's. [...] They really were a deterrent for me for going to university, not a motivation.

I think that's why I switched my degree 3 times! Seriously, [high school] guidance was brutal. It was bad. [...] I had no direction.

Interestingly, a few students reported transforming this negative experience into an incentive to go to university because they wanted to prove their guidance-counsellor wrong! Others spoke about the importance of 'one person who believes in you' to counteract bad advice from highschool counsellors:

She opened my eyes to other fields than policing. You can be a conservation officer, or fisheries. Or if you're interested in legal studies, you can be a lawyer. To me, that was like, you're the chair of [the] department looking at my marks, all 50's and 60's, and she's telling me I can do all these things if I really wanted to. She really opened up my eyes.

Others also spoke about being motivated by a desire to disprove peers who underestimated them during high school: A varsity-athlete talked about her motivation to go to university in order to disprove the "dumb jock" stereotype that her peers had labeled her with, while another wanted to disprove a stereotype in her home-community that "people from my family [don't] go to school; I wanted to prove that my family was a good family." All of these themes represent external/extrinsic motivations to pursue post-secondary, and students reported them as dominating within the first year or two of their university experience. Gradually, however, they experienced a shift toward internal/intrinsic motivations:

I went from my friends wanting me to go, and my family, and pressures of coming out of high school, to me wanting this for myself. Now it's like, trying to figure out my job, my career, what I want to do now. 
At some point you have to stop thinking about what people expect you to do, and start doing what you think is going to make you happy in the long run.

Most often, participants discovered that their true passion in life involved helping other people and making a positive difference in the world. For $4 / 8$ participants, they reported that this inspiration had come from past experiences in which someone had helped them. It inspired them to find a career in which they could do the same for others.

I want to be that adult that kids look up to and say: "that's who I want to be like".

I knew I had issues so I was like 'psychology, okay, I'll get into that for self-help purposes.' From there it was 'hey, I can see why this is so helpful and that's really what I want to do'. If I can help even one person, then I think that will be viewed as a success for me.

There's just something about helping somebody else. Internally I feel so much better and not just I feel better for myself but I feel better that I've actually done something to make the community or the world a better place.

\section{Conclusion}

We found that collaborating on this study was an effective way for the students to learn qualitative research skills. As a one-semester term-project, however, significant time-limitations were imposed. As a result, our sample best represents the perspectives of students who are: psychology majors, women, in their early twenties, and locals (rather than students who moved away from home for university). This leaves several other perspectives under-represented. When this course is taught again, we hope that the next class will want to explore the perspectives that were underrepresented in our study. We also discovered that it may not be authentic to compare 'traditional' versus 'non-traditional' students because many students meet criteria from both categories. Our findings also suggest that improved academic-counselling is needed that will encourage new students to explore widely and challenge themselves in their first few years of university to discover their intrinsic interests.

\section{References}

Munro, L. (2011). "Go boldly, dream large!”: The challenges confronting non-traditional students at university. Australian Journal of Education, 55(2), 115-131.

Pan, Y., \& Gauvain, M. (2012). The continuity of college students and its predictors: A three year longitudinal study. Learning and Individual Differences, 22(1), 92-99.

Saenz, V. \& Barrera, D. (2007). What we can learn from UCLA's "First in My Family" data? Retention in Higher Education, 21(9), 1-3. 
Woosley, S. A., \& Shepler, D. K. (2011). Understanding the early integration experiences of first-generation college students. College Student Journal, 45(4), 700-714.

York-Anderson, D. C., \& Bowman, S. L. (1991). Assessing the college knowledge of firstgeneration and second-generation college students. Journal of College Student Development, 32, 116-122. 